Pacific Journal of Mathematics

MULTIPLICATION ON CLASSES OF PSEUDO-ANALYTIC 


\section{MULTIPLICATION ON CLASSES OF PSUEDO-ANALYTIC FUNCTIONS}

\section{JOHN JEWETT}

Lipman Bers $[1,2]$ has formulated a theory of solutions of linear elliptic partial differential equations in terms of classes of psuedo-analytic functions on a plane domain $D$. The theory for each class of psuedoanalytic functions is based on the notion of a generating pair of Holder continuous complex valued functions $F$ and $G$ defined on $D$ and satisfying $\mathfrak{s}[\overline{F(z)} G(z)]>0$ in $D$.

If $w$ is any function defined on $D$, then there exist two real valued functions $\phi$ and $\psi$ such that $w$ can be written uniquely as

$$
w(z)=\phi(z) F(z)+\psi(z) G(z) .
$$

A function $w$ defined on $D$ is said to be $(F, G)$-psuedo-analytic (of the first kind) if a certain generalized derivative exists or equivalently if the equations

$$
\begin{aligned}
& \phi_{x} F_{1}-\phi_{y} F_{2}+\psi_{x} G_{1}-\psi_{y} G_{2}=0 \\
& \phi_{y} F_{1}+\phi_{x} F_{2}+\psi_{y} G_{1}+\psi_{x} G_{2}=0
\end{aligned}
$$

are satisfied in $D$, where the subscripts $x$ and $y$ refer to partial derivatives with respect to $x$ and $y$ and the subscripts 1 and 2 refer to the real and imaginary parts of the functions $F$ and $G$. If $F=1$ and $G=i$, these equations reduce to the Cauchy-Riemann equations.

Given a generating pair $(F, G)$ let $B$ denote the class of all functions which are $(F, G)$-psuedo-analytic. If $F=1$ and $G=i$, then $B$ is the class of analytic functions on $D$, which will be referred to in this paper as $A$.

Any $B$ has many of the properties of the ring of analytic functions. In particular very close analogues of the identity theorem, the Cauchy theorem, the Cauchy integral formula, the standard convergence theorems, and power series expansions have been proved.

With each class $B$ is associated a class $B^{\prime}$ of psuedo-analytic functions of the second kind. This association is made by a mapping $\eta$ of $B$ into $B^{\prime}$ defined by

$$
\eta(\phi F+\psi G)=\phi+i \psi .
$$

On the class $A$ of analytic functions this mapping is clearly the identity.

Each class $B$ is a vector space with the usual definition of addition

Received October 13, 1959. 
of functions and multiplication by scalars and $\eta$ is a vector space isomorphism of $B$ onto $B^{\prime}$. The class $A$ is a ring under the usual pointwise multiplication of functions. Since the classes of psuedo analytic functions each bear such marked resemblances to the class $A$ of analytic functions, the question arises as to whether there exist for other classes appropriate generalizations of the ordinary multiplications of function. We shall prove that if such a multiplication bears a certain slight resemblance to the point wise multiplication, then $B$ is multiplicatively isomorphic to $A$ under the mapping $\eta$ and conversely.

We denote the ordinary multiplication of functions by juxtaposition. Let $m$ denote any mapping from $B \times B$ to the set of all functions from $D$ to the plane. In particular let $m_{p}$ be the mapping defined as follows: if $w=\phi F+\psi G$ and $w^{\prime}=\phi^{\prime} F+\psi^{\prime} G$, let

$$
m_{p}\left(w, w^{\prime}\right)=\left(\phi \phi^{\prime}-\psi \psi^{\prime}\right) F+\left(\phi \psi^{\prime}+\psi^{\prime} \phi\right) G .
$$

TheOREM. Let $B$ be a system of psuedo-analytic functions on the plane domain $D$ and let $m$ be a multiplication on $B$ (any mapping from $B \times B$ to the set of all functions from $D$ to the plane). Let $m$ be associative and bilinear with respect to addition in $B$. Then a necessary and sufficient condition for the mapping $\eta$ to be a multiplicative isomorphism of $B$ onto the ring $A$ of all analytic functions on $D$ is that there exists a non-constant $w$ in $B$ such that $m(w, G)=m_{p}(w, G)$ and $m_{p}(w, G) \in B$.

The proof of this theorem will be preceded by a lemma.

Lemma. Suppose that for all $w$ and $w^{\prime}$ in $B, m\left(w, w^{\prime}\right)=m_{p}\left(w, w^{\prime}\right)$. Then the mapping $\eta$ defined above is an isomorphism of $B$ onto the ring $A$ of analytic functions on $D$ if and only if $F_{1}=G_{2}$ and $F_{2}=-G_{1}$.

Proof of Lemma. A simple calculation shows that $\eta$ is an isomorphism of $B$ onto $B^{\prime}$ if and only if $m=m_{p}$. So the condition concerning isomorphism in the lemma is that $B^{\prime}=A$.

By adding and subtracting terms involving $\psi$ the system (2) is seen to be equivalent to

$$
\begin{aligned}
& F_{1}\left(\phi_{x}-\phi_{y}\right)-F_{2}\left(\phi_{y}+\psi_{x}\right)+\psi_{y}\left(F_{1}-G_{2}\right)+\psi_{x}\left(F_{2}+G_{1}\right)=0 \\
& F_{1}\left(\phi_{y}+\psi_{x}\right)+F_{2}\left(\phi_{x}-\psi_{y}\right)+\psi_{y}\left(F_{2}+G_{1}\right)-\psi_{x}\left(F_{1}-G_{2}\right)=0 .
\end{aligned}
$$

First suppose $F_{1}=G_{2}$ and $F_{2}=-G_{1}$. Then this system becomes

$$
\begin{aligned}
& F_{1}\left(\phi_{x}-\psi_{y}\right)-F_{2}\left(\phi_{y}+\psi_{x}\right)=0 \\
& F_{1}\left(\phi_{y}+\psi_{x}\right)+F_{2}\left(\phi_{x}-\psi_{y}\right)=0 .
\end{aligned}
$$

It is clear that if $w^{*}=\phi+i \psi$ is analytic, then $\eta^{-1}\left(w^{*}\right)$ satisfies the system (4). Therefore $A \subset B^{\prime}$ 
Suppose then that $B^{\prime}$ contains a function $w=\phi+i \psi$ which at some point $z$ of $D$ does not satisfy the Cauchy-Riemann equations. For this point the system (4) is a system of homogeneous algebraic equations with a non zero determinant whose value is

$$
\left[\phi_{x}(z)-\psi_{y}(z)\right]^{2}+\left[\phi_{y}(z)+\psi_{y}(z)\right]^{2} .
$$

Hence the only solution at $z$ is the zero solution and thus

$$
\mathfrak{F}_{\mathfrak{m}}[\overline{F(z)} G(z)]=F_{1}^{2}(z)+F_{2}^{2}(z)=0
$$

which contradicts the definition of generating pair. Thus $B^{\prime} \subset A$ and we have proved that $A=B^{\prime}$.

Conversely suppose that $\eta$ is an isomorphism onto $A$ so that $A=B^{\prime}$. Let $w^{*}=\phi+i \psi$ be a non constant analytic function in $B^{\prime}$. Then the system (3) becomes for this $w^{*}$

$$
\begin{aligned}
& \psi_{y}\left(F_{1}-G_{2}\right)+\psi_{x}\left(F_{2}+G_{1}\right)=0 \\
& \psi_{y}\left(F_{2}+G_{1}\right)-\psi_{x}\left(F_{1}-G_{2}\right)=0 .
\end{aligned}
$$

If for some $z$ the equations $F_{1}(z)=G_{2}(z)$ and $F_{2}(z)=-G_{1}(z)$ do not both hold, then the determinant of this system is non-zero at $z$ and hence by continuity of $F$ and $G$ the determinant is non-zero in some neighborhood of $z$ and hence $\psi_{x}=\psi_{y}=0$ on this neighborhood. By the identity theorem for harmonic functions $\psi_{x}$ and $\psi_{y}$ must then be zero everywhere so that $\psi$ is constant. A similar argument demonstrates the constancy of $\phi$ so that $w^{*}$ is constant contrary to assumption. This completes the proof of the lemma.

Proof of Theorem. Suppose first that $\eta$ is a multiplicative isomorphism of $B$ onto the ring $A$ of analytic functions in $D$. Then as before $m$ is identically equal to $m_{p}$ so that for $w=\phi F+\psi G \in B$ we have $m(w, G)=-\psi F+\phi G$. Substituting this function for $\phi F+\psi G$ in the system (1) yields that $m(w, G)$ is in $B$ if and only if

$$
\begin{aligned}
& -\psi_{x} F_{1}+\psi_{y} F_{2}+\phi_{x} G_{1}-\phi_{y} G_{2}=0 \\
& -\psi_{y} F_{1}-\psi_{x} F_{2}+\phi_{y} G_{1}+\phi_{x} G_{2}=0 .
\end{aligned}
$$

By the lemma $F_{1}=G_{2}$ and $F_{2}=-G_{1}$. Using this to substitute for the $G$ 's in the system (6) we obtain the system (4) and this system must be satisfied because $\phi+i \psi$ is analytic. Thus if $w$ is in $B$ then so is $m(w, G)$ and the condition of the theorem is necessary.

Conversely suppose that there exists a non-constant $w$ in $B$ such that $m(w, G)=m_{p}(w, G)=-\psi F+\phi G$ and this function is in $B$. Then $\phi$ and $\psi$ satisfy both (1) and (6) and since $w$ is non-constant there must exist a $z$ such that this system of four equations has a non-zero solution, i.e., the determinant of this system must be zero. 
The determinant of this system is

$$
\left[\left(F_{1}-G_{1}\right)^{2}+\left(F_{2}+G_{1}\right)^{2}\right]\left[\left(F_{1}+G_{2}\right)^{2}+\left(F_{2}-G_{1}\right)^{2}\right] .
$$

Now $\mathfrak{J m}^{\mathrm{m}}(\bar{F} G)=F_{1} G_{2}-F_{2} G_{1}$ which must be everywhere positive since $F$ and $G$ form a generating pair. If the second factor of (7) is zero, then it follows that

$$
\Im \mathfrak{m}(\bar{F} G)=-F_{1}^{2}-F_{2}^{2}<0 .
$$

Hence the first factor must be zero and the lemma implies that $\eta$ is an isomorphism of $B$ onto $A$.

\section{BIBLIOGRAPHY}

1. Lipman Bers, Theory of Psuedo-analytic functions, Mimeographed Lecture Notes, New York University, 1953.

2. L Local Theory of Psuedo-analytic functions, Lectures on Functions of a Complex Variable, Ann Arbor, Michigan, 1955, pp. 213-244.

UNIVERSITY OF GEORGIA 


\section{PACIFIC JOURNAL OF MATHEMATICS}

\section{EDITORS}

David GILbarg

Stanford University

Stanford, California

\section{F. H. BRowneLL}

University of Washington

Seattle 5, Washington

\section{A. L. Whiteman}

University of Southern California Los Angeles 7, California

\section{J. PAIGe}

University of California

Los Angeles 24, California

\section{ASSOCIATE EDITORS}
E. F. BECKENBACH
T. M. CHERRY
D. DERRY

\author{
E. HEWITT \\ A. HORN \\ L. NACHBIN
}

\author{
M. OHTSUKA \\ H. L. ROYDEN \\ M. M. SCHIFFER
}

E. SPANIER

E. G. STRAUS

F. WOLF

\section{SUPPORTING INSTITUTIONS}

\author{
UNIVERSITY OF BRITISH COLUMBIA \\ CALIFORNIA INSTITUTE OF TECHNOLOGY \\ UNIVERSITY OF CALIFORNIA \\ MONTANA STATE UNIVERSITY \\ UNIVERSITY OF NEVADA \\ NEW MEXICO STATE UNIVERSITY \\ OREGON STATE COLLEGE \\ UNIVERSITY OF OREGON \\ OSAKA UNIVERSITY \\ UNIVERSITY OF SOUTHERN CALIFORNIA
}

\author{
STANFORD UNIVERSITY \\ UNIVERSITY OF TOKYO \\ UNIVERSITY OF UTAH \\ WASHINGTON STATE COLLEGE \\ UNIVERSITY OF WASHINGTON \\ AMERICAN MATHEMATICAL SOCIETY \\ CALIFORNIA RESEARCH CORPORATION \\ HUGHES AIRCRAFT COMPANY \\ SPACE TECHNOLOGY LABORATORIES \\ NAVAL ORDNANCE TEST STATION
}

\footnotetext{
Mathematical papers intended for publication in the Pacific Journal of Mathematics should be typewritten (double spaced), and the author should keep a complete copy. Manuscripts may be sent to any one of the four editors. All other communications to the editors should be addressed to the managing editor, L. J. Paige at the University of California, Los Angeles 24, California.

50 reprints per author of each article are furnished free of charge; additional copies may be obtained at cost in multiples of 50 .
}

The Pacific Journal of Mathematics is published quarterly, in March, June, September, and December. The price per volume (4 numbers) is $\$ 12.00$; single issues, $\$ 3.50$. Back numbers are available. Special price to individual faculty members of supporting institutions and to individual members of the American Mathematical Society: $\$ 4.00$ per volume; single issues, $\$ 1.25$.

Subscriptions, orders for back numbers, and changes of address should be sent to Pacific Journal of Mathematics, 2120 Oxford Street, Berkeley 4, California.

Printed at Kokusai Bunken Insatsusha (International Academic Printing Co., Ltd.), No. 6, 2-chome, Fujimi-cho, Chiyoda-ku, Tokyo, Japan.

PUBLISHED BY PACIFIC JOURNAL OF MATHEMATICS, A NON-PROFIT CORPORATION

The Supporting Institutions listed above contribute to the cost of publication of this Journal, but they are not owners or publishers and have no responsibility for its content or policies. 


\section{Pacific Journal of Mathematics}

\section{Vol. 10, No. $4 \quad$ December, 1960}

M. Altman, An optimum cubically convergent iterative method of inverting a linear bounded operator in Hilbert space . . . . . . . . . . . . . . . . . . . . . . . . . . 1107

Nesmith Cornett Ankeny, Criterion for rth power residuacity ................. 1115

Julius Rubin Blum and David Lee Hanson, On invariant probability measures I . . . . . 1125

Frank Featherstone Bonsall, Positive operators compact in an auxiliary topology ..... 1131

Billy Joe Boyer, Summability of derived conjugate series . . . . . . . . . . . . . . . . 1139

Delmar L. Boyer, A note on a problem of Fuchs . . . . . . . . . . . . . . . . . 1147

Hans-Joachim Bremermann, The envelopes of holomorphy of tube domains in infinite

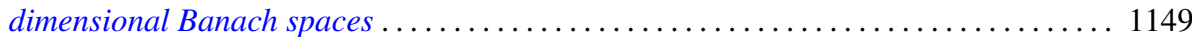

Andrew Michael Bruckner, Minimal superadditive extensions of superadditive

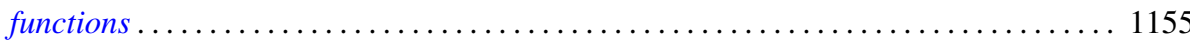

Billy Finney Bryant, On expansive homeomorphisms .................... 1163

Jean W. Butler, On complete and independent sets of operations in finite algebras . . . . . 1169

Lucien Le Cam, An approximation theorem for the Poisson binomial distribution ...... 1181

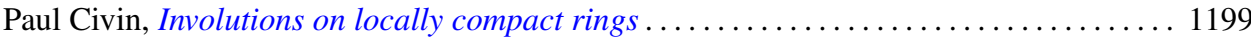

Earl A. Coddington, Normal extensions of formally normal operators . . . . . . . . . 1203

Jacob Feldman, Some classes of equivalent Gaussian processes on an interval ........ 1211

Shaul Foguel, Weak and strong convergence for Markov processes . . . . . . . . . . . 1221

Martin Fox, Some zero sum two-person games with moves in the unit interval ........ 1235

Robert Pertsch Gilbert, Singularities of three-dimensional harmonic functions . . . . . . . 1243

Branko Grünbaum, Partitions of mass-distributions and of convex bodies by

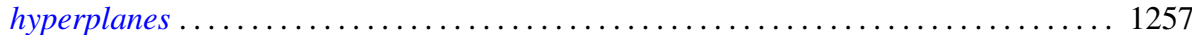

Sidney Morris Harmon, Regular covering surfaces of Riemann surfaces ........... 1263

Edwin Hewitt and Herbert S. Zuckerman, The multiplicative semigroup of integers

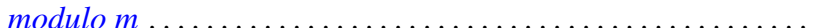

Paul Daniel Hill, Relation of a direct limit group to associated vector groups . ......... 1309

Calvin Virgil Holmes, Commutator groups of monomial groups . .

James Fredrik Jakobsen and W. R. Utz, The non-existence of expansive homeomorphisms

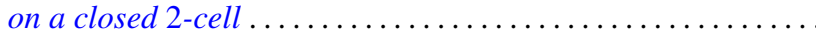

John William Jewett, Multiplication on classes of pseudo-analytic functions . . . . . . . 1323

Helmut Klingen, Analytic automorphisms of bounded symmetric complex domains . . . . 1327

Robert Jacob Koch, Ordered semigroups in partially ordered semigroups . . . . . . . . 1333

Marvin David Marcus and N. A. Khan, On a commutator result of Taussky and

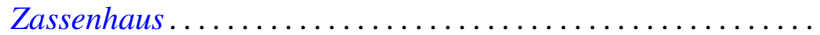

John Glen Marica and Steve Jerome Bryant, Unary algebras......

Edward Peter Merkes and W. T. Scott, On univalence of a continued fraction . . . . . . . 1361

Shu-Teh Chen Moy, Asymptotic properties of derivatives of stationary measures . . . . . 1371

John William Neuberger, Concerning boundary value problems . . . . . . . . . . . 1385

Edward C. Posner, Integral closure of differential rings . . . . . . . . . . . . . . . . . 1393

Marian Reichaw-Reichbach, Some theorems on mappings onto . . . . . . . . . . . . . 1397

Marvin Rosenblum and Harold Widom, Two extremal problems . . . . . . . . . . . . . . . . 1409

Morton Lincoln Slater and Herbert S. Wilf, A class of linear differential-difference

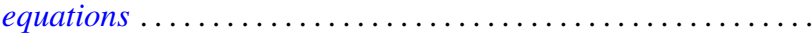

Charles Robson Storey, Jr., The structure of threads . . . . . . . . . . . . . . . . . . 1429

J. François Treves, An estimate for differential polynomials in $\partial / \partial z_{1},, \cdots, \partial / \partial z_{-} n \ldots \ldots 1447$

J. D. Weston, On the representation of operators by convolutions integrals . . . . . . . . 1453

James Victor Whittaker, Normal subgroups of some homeomorphism groups ......... 1469 